\title{
Composição e organização da clientela escolar em escolas municipais brasileiras: o que dizem os diretores ${ }^{1}$
}

\section{Composition and organization of school clientele in Brazilian municipal schools: what the headmasters say}

\author{
Sandra Maria Zákia Lian Souza* \\ Ângela Maria Martins**
}

\begin{abstract}
RESUMO
Com base na análise das respostas dos diretores de escolas municipais do país ao questionário contextual da Prova Brasil 2015, buscou-se conhecer critérios assumidos para a composição da clientela, nos estabelecimentos escolares, e sua organização por turmas, e refletiu-se sobre eventuais implicações das práticas adotadas para a democratização da educação. Trata-se de estudo exploratório das manifestações dos diretores, as quais foram tratadas por meio da quantificação da frequência das alternativas assinaladas no questionário, seguido da interpretação de seus conteúdos, com base em aportes de literatura correlata. $\mathrm{O}$ estudo traz pistas que indicam tendência à adoção, pelas escolas, de processos inclusivos de acolhimento e de alocação dos alunos, que expressam práticas democratizantes de gestão escolar. Registra, no entanto, limitações enfrentadas na análise das informações decorrentes de imprecisões presentes na formulação das questões.
\end{abstract}

Palavras-chave: Gestão escolar. Desigualdade escolar. Questionários contextuais. Clientela escolar. Composição de turmas.

1 Pesquisa intitulada Cenários de gestão de escolas municipais no Brasil, financiada pela Fundação Carlos Chagas, que contou com a participação dos seguintes pesquisadores: Angela Maria Martins (FCC/Unicid - Coord.); Cristiane Machado (Unicamp); Flávia Werle (Unisinos); Giselle Cristina Martins Real (UFGD); José da Silva Santos Júnior (UFGD); Maria Helena de Aguiar Bravo (FCC - bolsista); Miriam Bizzocchi (FCC) e Sandra Zákia Sousa (FEUSP).

* Universidade de São Paulo. São Paulo, São Paulo, Brasil. E-mail: sanzakia@usp.br. https:// orcid.org/0000-0001-5171-8301.

** Universidade Cidade de São Paulo. São Paulo, São Paulo, Brasil. E-mail: ange.martins@ uol.com.br. https://orcid.org/0000-0002-1267-8869. 


\begin{abstract}
Based on the analysis of municipal schools headmasters' answers to the contextual questionnaire Prova Brasil 2015, we sought to know which criteria have been assumed for the composition of the clientele in schools and their organization by groups, as well as to discuss possible implications of practices adopted for the democratization of education. It is an exploratory study of the headmasters' manifestations, which were treated by quantifying the frequency of the alternatives indicated in the questionnaire, followed by the interpretation of their content, based on the contributions from related literature. The study presents clues that indicate a trend towards the adoption, by the schools, of inclusive processes of reception and student allocation, expressing democratizing practices in school management. However, it also registers limitations faced in the analysis of the information, resulting from inaccuracies in the formulation of the questions.
\end{abstract}

Keywords: School management. School inequality. Contextual questionnaires. School clientele. Class composition.

Sem desconsiderar evidências de pesquisas que indicam ser o nível socioeconômico dos alunos o fator extraescolar que mais influencia suas aprendizagens, dado reiterado desde o relatório Coleman (1966), é preciso ressaltar a relevância de se analisar as práticas intraescolares que podem incidir na desigualdade de acesso e sucesso escolar dos alunos - reproduzindo ou intensificando desigualdades sociais - ou potencializar a garantia de uma educação de qualidade para todos. O reconhecimento da oportunidade de pesquisas que voltem a elucidar concepções, processos e práticas dominantes nos estabelecimentos escolares ensejou a realização de estudo que buscou revelar, com base em declarações de diretores de escolas municipais, procedimentos adotados para matrícula dos alunos e sua alocação por turmas, cujos resultados são tratados no presente artigo.

Nas últimas décadas, dispõe-se no Brasil de instrumentos que coletam, em âmbito do território nacional, informações relativas aos alunos, diretores, professores e escolas. Concomitante à criação do Sistema de Avaliação da Educação Básica (Saeb), instituído em 1990, com foco na testagem externa em larga escala do desempenho dos alunos em leitura e matemática, foram elaborados questionários contextuais para coletar, quando da aplicação das provas, informações relativas aos alunos, professores, diretores e escolas, além de características do trabalho pedagógico e de gestão escolar. Essas informações apresentam potencial para subsidiar o delineamento e o monitoramento das políticas públicas e práticas escolares e possibilitam o desenvolvimento de 
estudos sobre contextos educacionais, como os que se voltam à análise de fatores associados ao desempenho, dentre outras abordagens teórico-metodológicas ${ }^{2}$.

Do reconhecimento da potencialidade dos dados dos questionários contextuais como aportes para estudos de natureza abrangente, por se tratar de aplicação censitária, e do interesse em caracterizar cenários de gestão escolar em escolas municipais do país resultou a pesquisa que se propôs a mapear respostas declaradas pelos diretores de escolas municipais ao questionário da Prova Brasil 2015, com o intuito de apreender cenários de gestão escolar e analisar seu potencial de contribuição para a democratização da educação. ${ }^{3}$ Embora os elementos trazidos com esses questionários contextuais tenham limites para interpretação das informações produzidas - decorrentes da formulação e do escopo das questões, da sistemática de sua aplicação e até mesmo decorrentes das alterações feitas nas diversas versões de sua aplicação (FRANCO et al., 2003; KARINO et al., 2014; OLIVEIRA, 2015; BONAMINO, 2016), pela sua natureza e alcance trazem contribuições para uma aproximação com aspectos da realidade educacional do país.

$\mathrm{O}$ presente artigo trata de duas das vertentes que foram investigadas na referida pesquisa, concernentes aos critérios declarados pelos diretores para admissão de alunos na escola e a formação das turmas. Sobre esses processos, as evidências trazidas com a análise das respostas dos diretores não apoiam afirmações conclusivas, contudo, permitem elucidar tendências vigentes nas unidades escolares, o que será explorado no desenvolvimento do texto.

\section{Trilha metodológica}

Trata-se de estudo de natureza exploratória que tomou como referência as respostas de diretores municipais registradas no questionário do diretor, disponibilizadas nos microdados do Instituto Nacional de Estudos e Pesquisas Anísio Teixeira (Inep), para uma aproximação com práticas vigentes nas escolas por ocasião da matrícula dos alunos e sua posterior alocação por turmas. A definição de estudo exploratório oferecida por Apolinário (2004, p. 87) contribui para esclarecer a perspectiva da presente pesquisa: "Estudo que tem por objetivo aumentar a compreensão de um fenômeno ainda pouco conhecido, ou de um

2 https://portal.inep.gov.br/educacao-basica/saeb/instrumentos-de-avaliacao-acesso 19-

3 Retirado para garantir anonimato. 
problema de pesquisa ainda não perfeitamente delineado; estudo preliminar, estudo prospectivo".

O que se buscou foi conhecer como vem se dando a composição e a organização por turmas da clientela escolar e discutir suas eventuais implicações para a democratização escolar.

O interesse em investigar essas questões decorreu, dentre outras razões, do reconhecimento de repercussões, no trabalho escolar, das avaliações externas de desempenho dos alunos, que têm intensificado processos seletivos no interior das escolas. Pesquisa que se voltou a caracterizar iniciativas relacionadas à avaliação educacional desenvolvidas em anos recentes por municípios brasileiros (BAUER et al., 2017) revelou, dentre os achados, que as avaliações externas de desempenho de alunos têm sido valorizadas, de modo crescente, por gestores municipais. Dentre os usos feitos de seus resultados, destacam-se proposições que visam incidir nas práticas das escolas, com a perspectiva de induzir à obtenção de bons resultados pelos alunos, nas provas externas, sejam as aplicadas pelo próprio município, sejam as aplicadas por governos estaduais ou pelo governo federal.

Essa constatação apoiou a suposição de que as escolas tendem a se preocupar e se mobilizar para obtenção de bons resultados, o que não significa, necessariamente, melhoria de desempenho de todos os alunos, podendo se traduzir, dentre outros procedimentos, na seleção de alunos no momento de matrícula escolar ou, mesmo, na organização de turmas, com base no desempenho dos alunos (BARBOZA, 2006; CORTEZÃO, 2007; SOUZA; SILVA, 2007), sob a crença de favorecer a obtenção de melhores pontuações pela escola em avaliações externas.

Em 2015 houve um total de 55.693 respostas de diretores de escolas brasileiras ao questionário da Prova Brasil. Deste total, 34.502 (62\%) são diretores/as de escolas municipais de educação, os quais se constituíram em fonte do estudo em pauta. Do total de diretores/as municipais, 29.581 (85,2\%) estão lotados/as em escolas que oferecem os anos iniciais do Ensino Fundamental, e $13.739(39,8 \%)$ em escolas que oferecem os anos finais do Ensino Fundamental ${ }^{4}$.

As respostas dos diretores referentes a cada etapa de ensino foram computadas separadamente, sob o pressuposto de que práticas de diretores poderiam ter especificidades no que se refere a cada um dos níveis de ensino ofertados por escolas municipais. No entanto, as frequências de respostas não indicaram procedimentos específicos em relação às etapas do ensino fundamental, ou seja, os encaminhamentos do diretor, em relação aos aspectos aqui tratados, são semelhantes para os anos iniciais e finais do Ensino Fundamental.

4 O total de questionários tratados neste estudo (43.320) é superior ao número de diretores de escolas municipais respondentes (34.502), pois há casos em que o mesmo diretor atua em escolas que ofertam anos iniciais do Ensino Fundamental e anos finais do Ensino Fundamental. 
Dentre as questões presentes no questionário dos diretores em 2015, três delas exploram a disponibilidade de vagas na escola e os processos de acolhimento e de alocação dos alunos por turmas adotados pelos diretores. As questões 37 e 38 dão pistas em relação aos processos de acolhimento e de alocação dos alunos pelas escolas, respectivamente, sobre procedimentos adotados quando do ingresso/matrícula na escola e distribuição dos alunos por turmas. Associada a essas informações, há indicação, na questão 39, sobre a disponibilidade de vagas da escola, que permite supor a demanda existente e, com base no registro assinalado, inferir a possibilidade de expediente, por parte da gestão, a mecanismos de seleção de alunos que irão compor a clientela escolar.

As informações oriundas dessas questões apoiam a suposição de ter a escola um projeto inclusivo que acolha e interaja com a diversidade de particularidades dos alunos que a procuram ou um projeto que tende a julgá-las, nem sempre positivamente e, em consequência, recorrer a estratégias que reiterem diferenças e desigualdades individuais e sociais.

Uma escola de massa possui formas de tratamento dos alunos por mecanismos sutis que aprofundam as distâncias dos melhores em relação aos mais fracos. Um exemplo desse mecanismo é a concentração de alunos menos favorecidos e com mais baixo desempenho escolar em certos estabelecimentos ou, em certas turmas, formando classes homogêneas (DUBET, 2003). Com essa premissa é que se procedeu à discussão das informações registradas pelos diretores sobre práticas adotadas nas escolas, explorando-se seu potencial de minorar ou intensificar diferenças e desigualdades entre os alunos e, portanto, caracterizar seu potencial de contribuir para a democratização da educação.

Nota-se, no entanto, restrições enfrentadas na análise das informações, decorrentes da formulação das questões e orientação de resposta, ou seja: as questões fechadas foram acompanhadas de alternativas de resposta não necessariamente excludentes entre si, embora a solicitação feita aos diretores tenha sido a de assinalar apenas uma alternativa em cada questão, e dentre as alternativas apresentadas há a possibilidade do respondente assinalar a alternativa "outra", sem ser acompanhada de pedido de complementação da resposta.

\section{Critérios para a admissão de alunos na escola}

A criança ou jovem, ao chegar à escola, traz características individuais e também relacionadas à sua origem de classe, as quais, muitas vezes, se dis- 
tanciam dos valores e normas dominantes no contexto escolar. De acordo com Oliveira et al. (2013, p. 30),

[a] escola deve considerar tais características em suas práticas e ações, visando superar os eventuais efeitos negativos que tenham sobre o aprendizado do aluno. Ainda que as características do aluno tenham forte poder explicativo em si, elas não são justificativas para a escola "selecionar" seus alunos com o objetivo de obter melhores resultados.

A questão 37 do questionário contextual, ao indagar sobre o procedimento adotado pela escola para a admissão de alunos, processo que se dá de modo mais intenso no ingresso dos alunos no EF, remete a elementos que permitem inferir a existência ou a adoção, por parte da escola, de algum mecanismo de seleção dos alunos que a procuram. Embora esta seja uma prática não autorizada nas redes públicas, há "relatos de procedimentos, explícitos ou velados, que apontam nesse sentido" (OLIVEIRA et al., 2013, p. 30). A referida questão é assim colocada aos diretores:

NESTE ANO, QUAL FOI O CRITÉRIO PARA A ADMISSÃO DE ALUNOS NESTA ESCOLA?

a) Prova de seleção.

b) Sorteio.

c) Local de moradia.

d) Prioridade por ordem de chegada.

e) Outro critério. (BRASIL, 2015)

Para discussão da temática suscitada pela questão, como já informado, procedeu-se à identificação do percentual de respostas a cada uma das alternativas e à interpretação de seu conteúdo, com base em aportes de literatura correlata, referenciados no decorrer do artigo.

A aplicação de prova de seleção - alternativa A - revela a adoção de um procedimento de triagem de alunos que buscam o estabelecimento de ensino. Em especial, no caso de escolas que têm uma demanda superior ao número de vagas disponíveis, a aplicação de provas para selecionar "os mais aptos ou preparados" é um procedimento não raro adotado. Esta alternativa foi assinalada por $1,2 \%$ dos diretores de EFI e por 1,3\% dos diretores de EFII. 
A adoção de sorteio - alternativa B - foi a opção indicada por $0,4 \%$ do total de diretores de EFI e EFII, a qual revela que a escola não realiza qualquer influência para seleção dos ingressantes. Também, o registro de $27 \%$ dos diretores de EFI e de 25,6\% dos diretores de EFII de que a matrícula se dá respeitando a ordem de chegada - alternativa $\mathrm{D}$ - pode ser interpretado como acolhimento dos alunos, pela escola, sem qualquer discriminação.

A realização de matrícula setorizada, tendo em conta o local de moradia dos alunos -alternativa $\mathrm{C}$ - foi a prática indicada por $42,8 \%$ dos diretores de EFI e por $39,9 \%$ dos diretores de EFII. A concentração de respostas nessa alternativa é compreensível, pois se trata de um procedimento usual em redes de ensino, sendo este critério estabelecido em normas vigentes nas respectivas redes. Nesses casos, a escola tende a ter uma clientela composta por alunos de nível socioeconômico e cultural semelhante ao seu entorno, no entanto, essa normatização não impede a existência, em uma mesma área ou região, de escolas mais homogêneas e mais heterogêneas (ALVES et al., 2015; COSTA; KOSLINSKI, 2011, 2012; ÉRNICA; BATISTA, 2012; PADILHA et al., 2013) 5

No caso do registro, pelos gestores, da alternativa "outro critério", não é possível arriscar qualquer interpretação, posto que o respondente não explicita a prática utilizada pela escola, pois não lhe é solicitada complementação da resposta assinalada. Portanto, para cerca de $30 \%$ dos respondentes $(28,6 \%$ dos diretores de EFI e 32,7\% dos diretores de EFII) não se têm elementos para identificar o critério utilizado, o que demandaria informações não disponíveis no questionário, que tanto poderia corresponder às práticas não elencadas, quanto à combinação de procedimentos, visto que as alternativas não são excludentes - um diretor poderia usar métodos combinados, como sorteio e local de moradia, por exemplo.

Atentando-se aos limites de interpretação das respostas obtidas frente à imprecisão da formulação da questão no que se refere ao critério adotado pela escola para admissão de alunos, é possível inferir, considerando-se os percentuais de respostas dos diretores, que $29,8 \%$ dos que atuam no EFI e $34 \%$ dos que atuam no EFII estabelecem critérios próprios da escola para ingresso dos alunos. Isto pode representar uma triagem dos ingressantes, quais sejam: aqueles que assinalaram fazer seleção ou adotar "outro critério" de admissão, que excluem alternativas supostamente mais democráticas, como o sorteio, a ordem de chegada ou a matrícula setorizada.

5 Choukri Ben Ayed (2012), no artigo As desigualdades socioespaciais de acesso aos saberes: uma perspectiva de renovação da sociologia das desigualdades escolares, analisa o avanço dos conhecimentos sobre as desigualdades socioespaciais de acesso aos saberes na França. Realça que estudo das variações do aprendizado escolar em função dos contextos de escolarização não pode dissociar, nas análises, o impacto dos fatores sociais e espaciais. 
Além de registrar o critério para a admissão de alunos, os diretores informaram, na questão 38 , sobre a disponibilidade de vagas na escola, considerando a demanda por matrícula. A indagação foi assim apresentada aos respondentes:

\begin{abstract}
NESTE ANO, COMO FOI A SITUAÇÃO DA OFERTA DE VAGAS NESTA ESCOLA?

a) Após o processo de matrícula, a escola ainda tinha vagas disponíveis. b) A procura por vaga na escola preencheu todas as vagas oferecidas.

c) A procura por vaga na escola foi um pouco maior que as vagas oferecidas.

d) A procura por vaga na escola superou em muito o número de vagas oferecidas. (BRASIL, 2015).
\end{abstract}

Aproximadamente $60 \%$ dos respondentes (57,3\% para EFI e 58,9\% para EFII) assinalaram a alternativa $\mathrm{A}$, indicando não terem sido preenchidas todas as vagas oferecidas pela escola. De acordo com o Relatório educação para todos no Brasil 2000-2015 (2014), a redução das matrículas de alunos nas escolas de ensino fundamental pode ser explicada por dois fatores que ocorreram simultaneamente: a redução da taxa de natalidade no país e as iniciativas de políticas educacionais direcionadas à redução da distorção idade-ano. Nota-se, no entanto, que embora tenha ocorrido queda da taxa de natalidade e a quantidade de crianças em idade escolar esteja diminuindo, a tendência é de crescimento no atendimento a essa faixa etária.

Tiveram as vagas preenchidas $13,3 \%$ e $12,1 \%$ as escolas de EFI e EFII, respectivamente. Relacionando o contingente de respostas dadas às alternativas $\mathrm{A}$ e B com a questão relativa aos critérios de admissão de alunos, é possível supor que em $71 \%$ das escolas não há razões para a adoção de critérios de seleção de alunos para ingresso, visto que a demanda por vagas não supera a oferta. Contudo, 74,6\% do total de diretores de EFI e EFII que afirmam terem vagas disponíveis nas suas escolas, após o processo de matrícula, realizam "Prova de Seleção" e 38,4\% realizam "Sorteio".

Revelam situação inversa $29 \%$ dos diretores de EFI e EFII, que assinalaram as alternativas C (18,8\% EFI e 17,6\% EFII) e D (10,6\% EFI e 11,4\% EFII).

Após trazer indicações sobre procedimentos adotados pela gestão quando do ingresso dos alunos na escola, tratou-se da questão de número 39, que traz elementos que permitem compreender como, após a matrícula na escola, vem se dando a organização das turmas. 


\section{Alocação dos alunos por turmas}

Usualmente, nas redes de ensino, não há determinação por parte dos órgãos centrais de gestão relacionada à composição das turmas, cabendo à direção e ao corpo docente das escolas, a decisão quanto aos critérios a serem adotados. Uma aproximação com as opções que vêm sendo feitas pelas escolas, para agrupamento dos alunos nelas matriculados, é possibilitada por meio da apreciação das respostas assinaladas pelo diretor à questão assim apresentada:

NESTE ANO, QUAL FOI O PRINCIPAL CRITÉRIO UTILIZADO PARA FORMAÇÃO DAS TURMAS NESTA ESCOLA?

a) Homogeneidade quanto à idade (alunos com a mesma idade).

b) Homogeneidade quanto ao rendimento escolar (alunos com rendimento similar).

c) Heterogeneidade quanto à idade (alunos com idades diferentes).

d) Heterogeneidade quanto ao rendimento escolar (alunos com rendimentos diferentes).

e) Outro critério.

f) Não houve critério. (BRASIL, 2015).

A interpretação das respostas obtidas tem uma limitação decorrente da formulação desta questão, ou seja, embora a solicitação feita aos respondentes seja assinalar apenas uma alternativa, as opções apresentadas não são excludentes, pois contemplam procedimentos que podem ser adotados com diferentes combinações e finalidades distintas.

As alternativas que se referem à organização de classes homogêneas agrupar alunos da mesma idade ou agrupar alunos com rendimento similar tanto podem apontar para uma direção de não separação de alunos em razão de seu nível de desempenho escolar, quanto podem indicar a adoção de estratégia de segmentação, que tende a induzir a processos discriminatórios e seletivos no interior da escola.

A primeira alternativa, organização de classes homogêneas quanto à idade, assinalada por $32,6 \%$ dos diretores de EFI e por 34\% dos diretores de EFII - é interpretada, no âmbito deste estudo, como uma evidência de que os alunos estão ingressando na escola na idade esperada e seguindo sua trajetória escolar sem 
interrupções ou reprovações, o que é desejável, supondo-se que a permanência na escola esteja correspondendo a aprendizagens por parte do aluno ${ }^{6}$.

No entanto, essa interpretação deve ser relativizada, ao se ter em conta a possibilidade de que exceções à regra podem ser praticadas nas escolas. Exemplifica esse alerta a constatação feita por Costa e Koslinski (2006), com base em estudo desenvolvido na rede municipal do Rio de Janeiro. Esses autores (2006, p. 141) comentam que

[...] muitas escolas dividem suas turmas de acordo com a idade dos alunos, sob a argumentação de que alunos se desenvolvem melhor com colegas da mesma idade e em conformidade com preceitos pedagógicos em voga. Sabemos que essa prática informal, consequentemente, separa os alunos de acordo com suas trajetórias escolares - isto é, se os alunos entraram cedo ou tarde na escola, se já foram reprovados em alguma série, ou se já se evadiram da escola por algum tempo. Entretanto, quando conversamos sobre essa divisão com a diretora de uma das escolas pesquisadas, ela apontou que alguns alunos de bom rendimento, mesmo que sejam mais velhos, são encaminhados para as turmas " 01 ", do turno da manhã, o que sugere que a divisão de turmas também leva em conta a performance dos alunos.

A segunda alternativa, organizar classes homogêneas quanto ao rendimento escolar, apontada por aproximadamente $5 \%$ dos diretores, neste estudo, é sopesada como não desejável, considerando evidências de pesquisas que apontam, nas palavras de Crahay (2007, p. 203), ser ilusão "acreditar na eficácia das classes homogêneas quanto ao rendimento. Quando se obtém um resultado, em geral é em detrimento dos alunos fracos e é negativo pelo simples fato de ser resultante da resignação dos professores".

Crahay (2007, p. 186), ao explorar razões que apoiam a opção pela constituição de classes homogêneas, registra: "quando o professor está diante de uma classe composta de alunos de nível escolar homogêneo, ele pode mais facilmente encontrar atividades adequadas, bem como um ritmo de ensino que

6 A Emenda Constitucional 59 estabelece a matrícula compulsória na educação básica para o corte etário de 4 a 17 anos, assegurada inclusive sua oferta gratuita para todos os que a ela não tiveram acesso na idade própria. Aos seis anos de idade, tem início o ensino fundamental obrigatório, com duração de nove anos. (Lei $\left.{ }^{\circ} 11.274 / 2006\right)$. Portanto, o estudante que ingressar na idade certa no ensino fundamental e não tiver interrupções ou reprovações na trajetória escolar completa o ensino fundamental com 14 anos e o ensino médio com 17 anos. Para as crianças de 4 e 5 anos a matrícula é obrigatória na pré-escola. 
convenha a todos". Em relação às classes heterogêneas, há a suposição de que "todo mundo perderia": "os melhores porque seriam freados na sua progressão, e os mais fracos porque não conseguiriam seguir o ritmo dos outros e terminariam por recuar". Esses mesmos pressupostos apoiam, ainda, iniciativas de redes de ensino que adotam essa organização em alguns momentos da trajetória escolar dos alunos, usualmente um ano letivo, reunindo em uma dada classe alunos que apresentam graus de dificuldades escolares considerados semelhantes.

Como diz Lima (2016, p. 43), ao tratar da organização de turmas na escola básica,

[o] que pode não estar evidente para a direção e a equipe pedagógica é que através das decisões tomadas nesta etapa de organização da escola, que não são meramente técnicas, pode-se aprofundar ou reduzir as desigualdades sociais e escolares, ampliando-se ou tornando mais limitadas as oportunidades de aprendizagem para os alunos. Para Dubet (2008, p. 36), a organização de turmas homogêneas é um dos mecanismos engendrados pela escola capaz de produzir segmentação escolar, tendo em vista que "o reagrupamento dos alunos fracos na mesma classe limita seu progresso, quando simplesmente não o impede". Na perspectiva de uma escola que seja a mais justa possível, propugnada pelo autor, os professores aprendem a educar juntos alunos diferentes, atenuando os efeitos desiguais da competição meritocrática e combatendo a ideia de seletividade, de separação do "joio e do trigo", intrínsecas às instituições escolares.

Também há estudos que apontam haver relação entre a composição das turmas e desigualdades sociais, visto que "existe uma persistente tendência de as origens sociais e o capital cultural e social atraírem condições educacionais correspondentes" (GOMES, 2005, p. 302). Nessa perspectiva vale mencionar contribuições de pesquisas realizadas no Brasil, como as de Alves e Soares (2007), Costa e Kolinski (2008), Gomes (2005), Oliveira et al. (2013), Santos (2013) e Lima (2016).

Ao tratar de efeitos da composição da turma, Duru-Bellat (2005) comenta sobre resultados de estudos realizados na França, destacando efeitos do modo como diretores de estabelecimentos compõem as classes, em especial, para os alunos considerados fracos. Duru-Bellat (2005, p. 24) registra que

[o] modo como os diretores de estabelecimento compõem suas classes é, pois, importante. Ele pode assumir a forma oficialmente proibida (no collège, na França) e, portanto, frequentemente tabu, da constituição 
das classes homogêneas, prática que estudos recentes revelam ser frequentes no nível do collège (DURU-BELLAT; MINGAT, 1997). Ora, a constituição de classes hierarquizadas acadêmica e, ao mesmo tempo, socialmente tem interferência sobre os progressos dos alunos do collège: eles progridem mais quando escolarizados numa classe de nível médio elevado. Além disso, os progressos são melhores quanto mais elevada for a heterogeneidade da classe (mas este efeito é menos intenso que o precedente). Finalmente e acima de tudo, a frequência a uma classe heterogênea possui efeitos diversificados conforme o nível inicial dos alunos: os mais fracos "ganham" em frequentar esse tipo de classe enquanto, ao contrário, os mais fortes perdem com isso. Mas o que ganham os fracos é cerca de duas vezes mais importante do que o que perdem os fortes: os mais fracos podem ganhar até meio desvio-padrão da distribuição das notas conforme estejam numa classe muito forte ou muito fraca, enquanto a perda dos fortes será no máximo da ordem de um quarto de desvio-padrão.

Oportuno também mencionar que a própria organização e tratamento dado ao currículo escolar tende a variar de acordo com as expectativas que se tem em relação aos alunos. Nesse sentido, cita-se novamente o estudo de Duru-Bellat (2005, p. 25), que assim sintetiza essa problemática:

\begin{abstract}
Tanto no nível da classe quanto no nível do estabelecimento, sabe-se que, segundo o nível acadêmico e a composição social do público, a instrução proporcionada varia em quantidade e em qualidade, porque os docentes adaptam as práticas pedagógicas em função do suposto nível dos alunos. Em certos casos, a preocupação de adaptação do docente pode traduzir-se por uma diversificação não somente dos meios oferecidos ao aluno para atingir os objetivos, mas também dos próprios objetivos, que são mais modestos em relação aos alunos mais fracos.
\end{abstract}

As breves alusões às contribuições de pesquisas aqui mencionadas permitem ilustrar os riscos de se organizar turmas homogêneas, compostas por alunos com baixo desempenho, como estratégia que se apresenta com o fim de contribuir para que esses alunos enfrentem as dificuldades de aprendizagem, pois esta alternativa tende a confinar os alunos mais fracos ao fracasso escolar e a acentuar o peso das desigualdades sociais sobre as desigualdades escolares.

Essa perspectiva de análise foi tomada como referência para apreciação das respostas obtidas dos diretores quanto ao principal critério utilizado para formação das turmas na escola, em 2015. 
Reiterando os limites de interpretação das respostas obtidas, já mencionados, decorrentes da formulação da questão, vale observar que a opção por formação de turmas homogêneas foi a preponderante, no entanto, essa organização se baseia na idade dos alunos (32,6\% dos diretores de EFI e 34\% dos diretores de EFII) e não no seu rendimento similar (5,6\% dos diretores de EFI e 5,1\% dos diretores de EFII), o que pode resultar em classes heterogêneas quanto ao rendimento dos alunos, supondo-se que alunos de mesma idade não necessariamente tenham desempenho escolar semelhante. No entanto, como já assinalado, esta opção não exclui, necessariamente, a vigência de práticas com potencial de reforçar a segmentação escolar.

Embora não seja nova, e há muito tempo já venha sendo divulgada aos educadores, a constatação de que o princípio da homogeneidade não seja o mais desejável em uma perspectiva de democratização do ensino, é o que se evidenciou como preponderante nas respostas obtidas. As alternativas que apresentam como princípio a heterogeneidade, seja quanto a idade, seja quanto ao rendimento, juntas obtiveram pouco mais de $23 \%$ do total de respostas assinaladas, enquanto que em torno de $39 \%$ incidiram nas alternativas que mencionam homogeneização das turmas.

Em torno de 38\% dos diretores assinalaram alternativas de resposta "Outro critério" e "Não houve critério", o que não permite identificar as práticas adotadas para a formação das turmas na escola, em 2015.

\section{Considerações finais}

O que se buscou explorar por meio das respostas assinaladas pelos diretores nas questões relativas à composição e à organização da clientela escolar foram pistas que revelassem se as escolas vêm adotando - ou não - processos inclusivos de acolhimento e de alocação dos alunos, que expressem práticas democratizantes de gestão escolar, que propiciem a não discriminação e segmentação das crianças e jovens, promovendo sua aprendizagem.

Quanto à seleção de alunos para admissão na escola, o que se pode elucidar é que em torno de $70 \%$ das respostas mencionaram a não adoção de procedimentos discriminatórios. Essa constatação era até esperada, pois este é o percentual de respostas que indicaram que a escola não tem uma demanda por vaga superior ao número disponível.

No entanto, não é desprezível o número de respondentes que registraram a adoção de critérios próprios da escola para ingresso dos alunos, indicando 
triagem dos ingressantes, ou por meio de seleção ou por adoção de "outro critério" de admissão, os quais deixaram de assinalar alternativas supostamente mais democráticas, como o sorteio, a ordem de chegada ou a matrícula setorizada. Estudos que focalizem esses estabelecimentos escolares, desenvolvidos por meio de delineamentos específicos, são oportunos para se conhecer com precisão práticas usualmente adotadas pelas escolas para triagem dos alunos e as motivações subjacentes à sua adoção.

Quanto aos processos de formação de turmas, ou seja, indicação da opção por constituição de classes homogêneas ou heterogêneas, não há elementos que permitam aquilatar com segurança a tendência preponderante nas decisões das escolas, o que decorreu da imprecisão das alternativas de resposta apresentadas aos diretores. Foi possível, no entanto, identificar que, mesmo em percentual pequeno, há diretores que declararam a opção organizar classes homogêneas quanto ao rendimento escolar, o que revela uma prática que tende a intensificar desigualdades, casos estes que merecem aprofundamento analítico em estudos subsequentes. Também, merece desdobramento pesquisas que permitam esclarecer respostas assinaladas por aproximadamente $40 \%$ de diretores para os quais não é possível inferir que procedimentos foram adotados para a formação das turmas na escola, não sendo possível inferir a preponderância de princípios de homogeneidade ou heterogeneidade.

É oportuno registrar que embora as respostas dos diretores ao questionário contextual da Prova Brasil possam ser eivadas pela proximidade entre a direção escolar e os órgãos gestores municipais, em especial quando estes acessam a função por indicação ${ }^{7}$, pela abrangência nacional têm potencial de apoiar inferências de tendências que aportam subsídios para políticas educacionais e práticas escolares. Daí a importância de que seja um instrumento de coleta de informações válido e confiável, o que remete a necessidade de aprimoramento em sua elaboração e aplicação. Talvez, a "ênfase excessiva nas medidas cognitivas em detrimento das medidas sociais, escolares e pedagógicas" (BONAMINO, 2016), presente no Saeb, possa explicar, em parte, as imprecisões presentes em sua formulação, o que se evidenciou no estudo em pauta. Considerando o potencial desse instrumento para elucidar fatores contextuais que incidem na produção da educação escolar, em âmbito nacional e de cada estabelecimento de ensino, fica o alerta quanto à importância e à oportunidade de seu aprimoramento.

7 Em 2015, assumiram a direção das escolas apenas por indicação 56\% dos diretores de EFI e $61,6 \%$ dos diretores de EFII. 


\section{REFERÊNCIAS}

ALVES, M. T. G.; SOARES, J. F. Efeito-escola e estratificação escolar: o impacto da composição de turmas por nível de habilidade dos alunos. Educação em Revista, Belo Horizonte, v. 45, p. 25-58, jun. 2007.

ALVES, L.; BATISTA, A. A. G.; RIBEIRO, V. M.; ÉRNICA, M. Seleção velada em escolas públicas: práticas, processos e princípios geradores. Educação e Pesquisa, São Paulo, v. 41, n. 1, p. 137-152, jan./mar. 2015.

APOLINÁRIO, F. Dicionário de metodologia científica: um guia para a produção do conhecimento científico. São Paulo: Atlas, 2004.

AYED, C. B. As desigualdades socioespaciais de acesso aos saberes: uma perspectiva de renovação da sociologia das desigualdades escolares? Educ. Soc. [online], v. 33, n. 120, p. 783-803, 2012.

BARBOZA, E. M. R. A composição das turmas e o desempenho escolar na rede pública de ensino de Minas Gerais. 2006. 110 f. Tese (Doutorado em Educação) - Pontifícia Universidade Católica do Rio de Janeiro, Rio de Janeiro, 2006.

BONAMINO, A. A evolução do Saeb: desafios para o futuro. Em Aberto, Brasília, v. 29, n. 96, p. 113-126, maio/ago. 2016.

BAUER, A. et al. Iniciativas de avaliação do ensino fundamental em municípios brasileiros: mapeamento e tendências. Rev. Bras. Educ., Rio de Janeiro, v. 22, n. 71, e227153, 2017.

BRASIL. Instituto Nacional de Estudos e Pesquisas Educacionais Anísio Teixeira (INEP). Sistema de Avaliação da Educação Básica. Questionário do diretor. 2015. Disponível em: <http://download.inep.gov.br/educacao_basica/prova_brasil_saeb/questionarios/ questionario_diretor.pdf $>$.Acesso em: 05 jan. 2017.

COLEMAN, J. S. et al. Equality of Educational Opportunity. Washington: US Government Printing Office. 1966.

CORTEZÃO, L. O arco-íris na sala de aula? Processos de organização de turmas: reflexões críticas. Cadernos de Organização e Administração Educacional, Portugal. n.1, p.1-15, 2007. Disponível em: <http://www.miniwebcursos.com.br/artigos/livros/caderno8.pdf>. Acesso em: 06 fev. 2018.

COSTA, M. da; KOSLINSKI, M. Entre o mérito e a sorte: escola, presente e futuro na visão de estudantes do Ensino Fundamental do Rio de Janeiro. Revista Brasileira de Educação, Rio de Janeiro, v. 11, n. 31, p. 133-201, jan./abr. 2006.

COSTA, M. da; KOSLINSKI, M. Prestígio escola e composição de turmas - explorando a hierarquia em redes escolares. Estudos em Avaliação Educacional, São Paulo, v. 19, n. 40, p. 305-330, maio/ago. 2008.

COSTA, M. da; KOSLINSKI, M. Quase mercado oculto: disputa por escolas “comuns" no Rio de Janeiro. Cadernos de Pesquisa, São Paulo, v. 41, n. 142, p. 246-266, jan./abr. 2011. 
COSTA, M. da; KOSLINSKI, M. Escolha, estratégia e competição por escolas públicas. Pro-Posições, Campinas, v. 23, n. 2, p. 195-213, maio/ago. 2012.

CRAHAY, M. Qual pedagogia para os alunos em dificuldade escolar? Cadernos de Pesquisa, v. 37, n. 130, p. 181-208, jan./abr. 2007.

DUBET, F. A Escola e a exclusão. Cadernos de Pesquisa, São Paulo, v. 119, p. 9-27, 2003.

DURU-BELLAT, M. Amplitude e aspectos peculiares das desigualdades sociais na escola francesa. Educação e Pesquisa, São Paulo, v. 31, n. 1, p. 13-30, jan./abr. 2005.

ÉRNICA, M.; BATISTA, A. A. G. A escola, a metrópole, a vizinhança vulnerável. Cadernos de Pesquisa, São Paulo, v. 42, n. 146, p. 640-666, maio/ago. 2012.

FRANCO, C.; FERNANDES, C.; SOARES, J. F.; BELTRÃO, K.; BARBOSA, M. E.; ALVES, M. T. G. O referencial teórico na construção dos questionários contextuais do Saeb 2001. Estudos em Avaliação Educacional, n. 28, p. 39-74, 2003.

GOMES, C. A. Desseriação escolar: alternativa para o sucesso? Ensaio: Aval. Pol. Públ. Educ., Rio de Janeiro, v. 13, n. 46, p. 11-38, mar. 2005.

KARINO, C. A.; VINHA, L. G. do A.; LAROS, J. A. Os questionários do Saeb: o que eles realmente medem? Estudos em Avaliação Educacional, São Paulo, v. 25, n. 59, p. 270-297, set./dez. 2014.

LIMA, M. de F. M. de. Correção de Fluxo na Rede Pública Municipal do Rio de Janeiro (2009-2014): aspectos da política e as trajetórias dos alunos. 2016. Tese (Doutorado em Educação) - Pontifícia Universidade Católica, Rio de Janeiro, 2016.

OLIVEIRA, A. C. P. de. As relações entre Direção, Liderança e Clima Escolar em escolas municipais do Rio de Janeiro. 2015. 284 p. Tese (Doutorado em Educação) - Pontifícia Universidade Católica, Rio de Janeiro, 2015.

OLIVEIRA, R. P. et al. Análise das desigualdades intraescolares no Brasil. São Paulo: Fundação Victor Civita, 2013.

PADILHA, F. et al. Efeito do território sobre as desigualdades escolares: mudanças no caso de São Miguel Paulista de 2007 a 2009. Revista Olh@res, Guarulhos, Unifesp, v. 1, n.2, p. 8-30, 2013.

SANTOS, M. P. dos. Programa PIC da rede municipal de ensino de São Paulo: superação do fracasso escolar? 2013. Dissertação (Mestrado em Educação) - Universidade Cidade de São Paulo, 2013.

SOUZA, A. de M.; SILVA, G. F. da. Considerações sobre a importância da turma no desempenho dos alunos em escolas municipais. Revista Electrónica Iberoamericana sobre Calidad, Eficacia y Cambio en Educación, v. 5, n. 2e, p. 1-8, 2007.

Texto recebido em 13 de março de 2018.

Texto aprovado em 03 de junho de 2018. 